\title{
THE CHANGES IN THE BLOOD PRESSURE AND IN THE RENAL BLOOD FLOW AND GLOMERULAR FILTRATION RATE OF HYPERTENSIVE PATIENTS FOLLOWING UNILATERAL NEPHRECTOMY
}

\author{
BY MEYER FRIEDMAN, ARTHUR SELZER, HENRY KREUTZMANN, AND \\ J. J. SAMPSON \\ WITH THE TECHNICAL ASSISTANCE OF P. BLAKESLEE \\ (From the Harold Brunn Institute for Cardio-Vascular Research, Mount Zion Hospital, \\ San Francisco)
}

(Received for publication September 16, 1941)

In 1937 Butler (1) reported two cases of hypertension associated with unilateral kidney disease in which the hypertension was apparently abolished by the removal of the affected kidney. Since that time, there have been numerous reports (2 to 6 ) concerning the blood pressure changes occurring after the extirpation of a single diseased kidney in hypertensive patients. Although marked reductions in blood pressure have been reported following this type of operation, it appears that in the majority of cases the blood pressure of these patients had not returned to a normotensive level after the extirpation of the affected kidney. Indeed, Schroeder and Fish (6) in an analysis of previously published reports and a study of their own patients came to the conclusion that the efficacy of this particular surgical measure was very limited. Wilson and Byrom (7) and Friedman, Jarman and Klemperer (8) also reported that in their experimental animals the resulting hypertension from unilateral kidney derangement did not entirely disappear when the affected kidney was removed. These observers were inclined to believe that the persistence of the hypertension in their animals was related to the organic changes in the arterioles of the remaining kidney, which occurred during the prior existence of hypertension.

Since the hypertension present in individuals with unilateral kidney disease has been assumed to be due initially to this deranged kidney, it was thought advisable to study the renal hemodynamics in such hypertensive patients, both before and after the removal of the diseased kidney. In this communication, the results of such a study, together with the blood pressure changes following unilateral nephrectomy, are reported.

\section{METHODS}

Each of the five patients studied received a thorough physical and laboratory examination, and the diagnosis of unilateral kidney disease was definitively established by intravenous and retrograde urography.

The effective renal blood flow and the rate of glomerular filtration were determined by the diodrast ${ }^{1}$ and inulin clearances, respectively. The same procedures as described in a previous report (9) were followed. A blood pressure reading was obtained at the beginning and at the end of clearance determinations and the pressure values recorded in Table I-A represent the mean of these two readings.

The clearance values of the separate kidneys were also obtained by ureteral catheterization in three of the five patients. With the exception of one patient, the clearance determinations were performed upon each patient three times-immediately before nephrectomy, 13 to 19 days after nephrectomy and again 56 to 135 days following nephrectomy. Thus the immediate and late effects of the nephrectomy upon the hemodynamics of the remaining kidney were followed. All clearance values were adjusted to 1.73 square meters of surface area.

\section{CASES}

Five hypertensive patients with unilateral kidney disease were studied. The pertinent observations in each case are detailed below.

Case 1. C. P., male, age 24 years.

History. The patient was symptomless and the hypertension was discovered on routine physical examination.

Positive findings on examination. The blood pressure before operation ranged from $130 / 100$ to $180 / 120$. The retinal arteries were normal in appearance. Intravenous and retrograde urography revealed an atrophic left kidney and a hypertrophied right kidney. Differential PSP revealed 22 per cent excretion of the dye from the right kidney with but a trace from the left kidney in 30 minutes. Microscopic and chemical examination of the voided urine revealed no abnormalities.

1 The diodrast used in these experiments was given to us by the Winthrop Chemical Company. 
Course. The left kidney was removed on February 14, 1941. Following the operation, the patient's pressure decreased slightly but not significantly. When examined on April 25, 1941, the blood pressure was 160/100.

Pathological study of removed kidney. The removed kidney appeared grossly hypoplastic. On microscopic examination, there was evidence of chronic inflammation. No arteriolar disease observed.

Case 2. C. S., male, age 34 years.

History. The patient was discovered to have hypertension on routine physical examination. $\mathrm{He}$ had no symptoms and was known to have had a normal blood pressure in 1939.

Positive findings on examination. The blood pressure before operation ranged from $140 / 120$ to $165 / 125$. Retinal arteries were slightly attenuated with slight degree of $\mathrm{A}-\mathrm{V}$ impression. Intravenous and retrograde urography revealed a large hydronephrotic left kidney with widely dilated calyces. The right kidney appeared enlarged, but otherwise normal. Catheterized urine specimens from the separate kidneys revealed no microscopic or chemical abnormalities, and were bacteria-free.

Course. The patient was first operated upon February 20,1941 , at which time a leaf of redundant pelvic mucosa was found obstructing the ureter at its junction with the kidney pelvis. The obstruction was relieved, and the dilated pelvis was reduced in size by partial resection. Despite the relief of the hydronephrosis, the hypertension persisted. The patient was again operated upon on May 28,1941 , and the left kidney was removed. The patient's blood pressure decreased following the nephrectomy and has remained reduced. When examined on July 15, 1941, the blood pressure was $130 / 90$. The renal clearance determinations performed upon this patient were done before and after the second operation.

Pathological study of removed kidney. The removed kidney weighed 175 grams. There was some thinning of the cortex, and the pelvis and calyces were markedly enlarged. Microscopic examination of the kidney revealed areas of chronic inflammation, but the glomeruli were normal in appearance. The smaller arteries and arterioles also were normal in appearance. Because this kidney was subjected to prior surgical measures the evidences of present infection were probably due to the nephrostomy drainage.

Case 3. J. G., male, age 18 years.

History. The patient had observed increasing breathlessness on exertion for one year.

Positive findings on examination. The blood pressure before operation ranged from $180 / 114$ to $258 / 154$. There was slight attenuation of retinal arteries but otherwise there were no abnormalities. Intravenous and retrograde urography revealed a normal right kidney, but a small and atrophic left kidney. Differential PSP revealed 22 per cent excretion of the dye from the right kidney and 8 per cent excretion from the left kidney in 30 minutes. Catheterized urine specimens from the separate kidneys revealed no microscopic or chemical abnormalities and were bacteria-free.
Course. The patient was operated upon March 11, 1941, and an atrophic kidney was removed. Immediately following the operation, the blood pressure fell from 208/140 to $120 / 70$, but at the end of one week the pressure rose to $160 / 90$. In the succeeding months it has ranged from $130 / 80$ to $160 / 100$. When last examined on July 26,1941 , the blood pressure was $160 / 110$.

Pathological study of removed kidney. The kidney weighed 40 grams. The cortex was markedly distorted by old areas of scarring in which obliterated tubules, arteries and glomeruli could still be identified. Throughout the medulla and the cortex, small collections of plasma cells and lymphocytes were seen. The smaller arteries and arterioles were seen to be the seat of marked arteriosclerosis, consisting chiefly of subintimal hyalinization with partial obliteration of the vessel lumen.

Case 4. C. B., female, age 34 years.

History. Patient was operated upon in August, 1939, at which time a calculus was removed from the pelvis of the left kidney. At that time she had a normal blood pressure, but when examined again in January, 1940, it was observed that her blood pressure was $210 / 130$. Since that time the pressure has remained consistently elevated.

Positive findings on examination. The blood pressure before operation ranged from $170 / 95$ to $220 / 110$. The retinal arteries were attenuated with moderate $A-V$ impression. Intravenous and retrograde urography revealed a normal right kidney, but the upper calyces of the left kidney appeared dilated. Catheterized urine specimens from the separate kidneys revealed no microscopic or chemical abnormalities.

Course. The patient was operated upon April 9, 1941, at which time it was observed that the left kidney was surrounded by a dense scar capsule. Following the operation, the blood pressure decreased to $120 / 75$ and in the succeeding months, it has increased slightly. When last examined on June 23, 1941, the blood pressure was 150/90.

Pathological study of removed kidney. The kidney weighed 124 grams. The cortex had many depressed, irregular areas covered by scar tissue. On microscopic examination, many areas of the kidney were seen to be filled with lymphocytes and atrophic tubules. The glomeruli appeared normal and there was no evidence of arteriolar sclerosis.

Case 5. M. F., male, age 34 years.

History. For the past several years the patient had observed increasing dyspnea on exertion. The duration of the hypertension could not be ascertained but in 1936 the patient passed a small renal calculus.

Positive findings on examination. The blood pressure before operation ranged from $195 / 135$ to $250 / 150$. The retinal arteries were tortuous and irregular with marked $\mathrm{A}-\mathrm{V}$ impression. Intravenous and retrograde urography revealed a normal appearing right kidney but a calculus was observed in the pelvis of the left kidney which appeared to obstruct the flow of urine at the uretero-pelvic orifice. The pelvis and calyces of the left kidney were also markedly dilated. An Addis count of a 24-hour urine collection showed 100,000 casts, 71 million red blood cells and 13 million white blood cells. 
Course. The patient was operated upon June 20, 1941, and the left kidney was removed. The blood pressure fell to $130 / 90$ immediately following the operation, but on June 28,1941 , it had again increased to $160 / 110$. Since then, the pressure has continued to remain somewhat below the pre-operative range but it is questionable whether the reduction is significant. When last examined on $\mathrm{Au}$ gust 15, 1941, the blood pressure was 185/120.

Pathological study of the removed kidney. Microscopic examination of the removed kidney revealed small foci of lymphocytes and plasma cells diffusely distributed throughout the medulla and cortex. There was some obliteration of glomeruli observed. There was also severe involvement of both the smaller arteries and arterioles consisting of subintimal hyalinization, with marked encroachment upon the vessel lumen. The smaller arteries also showed considerable hyperplasia of the media.

\section{RESULTS}

A. The renal clearance determinations before unilateral nephrectomy

As Table I-A indicates, there was considerable variation in the blood pressure level of each pa- tient as determined during his hospital stay before operation. At the time of the clearance determinations the average blood pressure of the entire series was $173 / 117$ (range : $150 / 100$ to $220 / 135$ ).

The total effective renal blood flow (both kidneys) was found to vary considerably in the five patients studied (Table I-A). Thus, in Cases 1, 2,3 and 5 there was a diminution in the effective renal blood flow, the values being, respectively, $720,522,665$ and $675 \mathrm{cc}$. per minute, whereas in Case 4, the flow was 1073 cc. per minute, a value within the normal limits. In general, it appeared that the diminution in the flow was related to the severity of the hypertension (10) rather than to the specific pathology of the kidney. The renal blood flow determinations of the separate kidneys in three of the five patients (Table I-B) indicated that the blood flow in the apparently normal kidney was greater than in the diseased kidney.

The total inulin clearance (both kidneys) also was found to vary markedly (Table I-A). Thus,

TABLE I

A. Total renal clearance determinations before and after unilateral nephrectomy

\begin{tabular}{|c|c|c|c|c|c|c|c|c|c|c|c|c|c|c|c|c|c|c|}
\hline \multirow[b]{2}{*}{ Patient } & \multirow[b]{2}{*}{ Age } & \multicolumn{5}{|c|}{ Before unilateral nephreotomy } & \multicolumn{6}{|c|}{ After unilateral nephrectomy (13-19 days) } & \multicolumn{6}{|c|}{ After unilateral nephreotomy (56-135 days) } \\
\hline & & 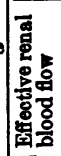 & 量。 & 害: & 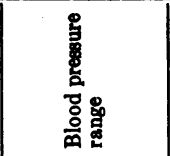 & 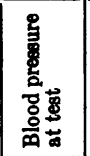 & 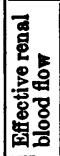 & 虽。 & 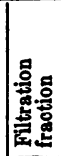 & 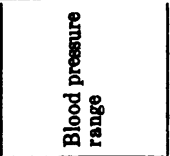 & 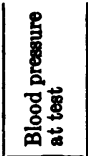 & 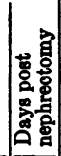 & 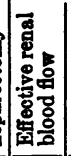 & 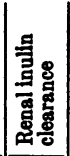 & 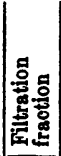 & 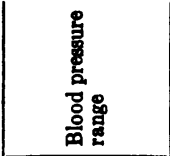 & 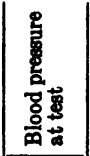 & 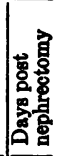 \\
\hline (1) F.P. & 24 & $\begin{array}{l}c c . \\
\text { per } \\
\min - \\
\text { ute } \\
720\end{array}$ & \begin{tabular}{|c|}
$c c$. \\
per \\
min \\
ute \\
83.0
\end{tabular} & $\begin{array}{l}\text { per } \\
\text { cent } \\
21.9\end{array}$ & $\begin{array}{c}\text { mm. Hg } \\
130 / 100-180 / 120\end{array}$ & $\begin{array}{c}\operatorname{mm}_{B g} \\
150 / 100\end{array}$ & $\begin{array}{c}c e . \\
\text { per } \\
\text { min- } \\
\text { ute }\end{array}$ & $\begin{array}{l}\text { ce. } \\
\text { per } \\
\text { min- } \\
\text { ute }\end{array}$ & per & $m m . H g$ & $\underset{H \cdot}{m_{j}}$ & & $\begin{array}{c}c c . \\
\text { per } \\
\text { min- } \\
u t e \\
965\end{array}$ & $\begin{array}{c}c c . \\
\text { per } \\
\text { min- } \\
\text { ute } \\
133.0\end{array}$ & $\begin{array}{c}\text { per } \\
\text { cent } \\
20.9 \\
\end{array}$ & $\begin{array}{c}\text { mm. Ho } \\
142 / 98-160 / 100\end{array}$ & \begin{tabular}{|c|}
$\underset{H m}{m g}$ \\
$160 / 100$
\end{tabular} & 70 \\
\hline (2) C.S. & 34 & 522 & 118.0 & 31.8 & $145 / 120-165 / 125$ & $155 / 120$ & 590 & 74.5 & 17.8 & $120 / 80-140 / 95$ & $130 / 90$ & 19 & 588 & 97.3 & 22.4 & $120 / 78-130 / 90$ & $128 / 90$ & 56 \\
\hline (3) J.G. & 18 & 665 & 114.0 & 31.3 & $180 / 114-258 / 154$ & $220 / 135$ & 1040 & 80.0 & 14.8 & $120 / 80-160 / 100$ & $150 / 90$ & 14 & 875 & 75.0 & 15.6 & $130 / 80-160 / 110$ & $160 / 110$ & 135 \\
\hline (4) G.B.* & 34 & 1073 & 78.0 & 14.1 & $170 / 95-220 / 110$ & $170 / 95$ & 1040 & 63.5 & 10.1 & $120 / 75-130 / 90$ & $130 / 85$ & 13 & 1025 & 103.8 & 18.1 & $125 / 75-150 / 80$ & $150 / 80$ & 74 \\
\hline (5) M.F. & 34 & 675 & 132.0 & 28.0 & $195 / 135-250 / 150$ & $195 / 135$ & 381 & 68.7 & 24.0 & $170 / 105-200 / 120$ & $170 / 120$ & \begin{tabular}{l|l}
0 & 19
\end{tabular} & 422 & 76.0 & 27.6 & $185 / 120-200 / 130$ & $185 / 120$ & 57 \\
\hline
\end{tabular}

* Female.

B. Renal clearance determinations of each kidney before unilateral mephrectomy

\begin{tabular}{|c|c|c|c|c|c|c|}
\hline \multirow[b]{2}{*}{ Patient } & \multicolumn{3}{|c|}{ Diseased kidney } & \multicolumn{3}{|c|}{ Normal kidney } \\
\hline & 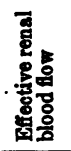 & 量8 & 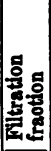 & 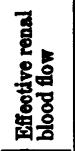 & 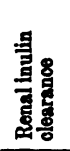 & 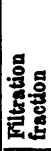 \\
\hline (1) F.P. & $\underset{\substack{\text { per } \\
\text { minute } \\
14}}{c}$ & $\begin{array}{c}c c . \\
\text { per } \\
\text { minute } \\
6.44\end{array}$ & $\begin{array}{l}\text { per } \\
\text { cent } \\
46\end{array}$ & $\begin{array}{c}c c . \\
\text { per } \\
\text { minuts } \\
638\end{array}$ & $\begin{array}{c}c c . \\
\text { per } \\
\text { minute } \\
76.7\end{array}$ & $\begin{array}{c}\text { pre } \\
\text { cont } \\
21.9\end{array}$ \\
\hline (4) C.B. & 414 & 24.20 & 10 & 659 & 67.2 & 17.6 \\
\hline (5) M.F. & 246 & & & 334 & & \\
\hline
\end{tabular}


in Cases 1 and 4, the inulin clearance was considerably diminished, being 83.0 and $78.0 \mathrm{cc}$. per minute, respectively. However, in Cases 2, 3 and 5 , the clearance values were within the limits of normal, being 118,114 , and $132.0 \mathrm{cc}$. per minute, respectively. The clearance determinations of the separate kidneys in Cases 1 and 2 (Table I-B) indicate that, although the inulin clearance was greater than normal in the unaffected kidney, it was reduced in the diseased kidney.

The filtration fraction was high in Cases 2, 3 and 5 , being $31.8,31.3$ and 28 per cent, respectively. In Case 1 the filtration fraction was 21.9 per cent and in Case 4, it was but 14.1 per cent. The reduction in the inulin clearance of these last two cases accounts for the lower filtration fraction values.

\section{$B$. The renal clearance determinations after unilateral nephrectomy}

It is apparent from Table I-A that, in the four patients studied immediately after nephrectomy (13 to 19 days) and while they were still hospitalized, there was a reduction in blood pressure. It was significantly reduced in three cases (Cases $2,3,4$ ) and the range of pressure was slightly reduced in the fourth case (Case 5). However, it should be emphasized that all were potentially or actually hypertensive. In the succeeding weeks and months little change could be detected in the pressure values of these four patients. The remaining Case (Case 1), when followed later, showed no significant reduction in his pressure as compared to the pre-operative level. Thus, in this series, although four of the five patients had a reduction in blood pressure after operation, only in three cases was it marked. Finally, none had a normal blood pressure when last examined, although Cases 2 and 4 were observed at times to have had a normal blood pressure.

The renal blood flow was studied in four of the five patients (Table I-A) after operation (13 to 19 days). It is of interest that, in those cases showing marked reduction in hypertension, the renal blood flow remained essentially the same or increased. Thus in Cases 2, 3 and 4, the renal blood flow was, respectively, 522, 665 and $1073 \mathrm{cc}$. per minute before and 590, 1040 and $1040 \mathrm{cc}$. per minute after the extirpation of the diseased kid- ney. However, in Case 5, the renal blood flow was $675 \mathrm{cc}$. per minute before, and $381 \mathrm{cc}$. per minute after operation. In this latter case, there was also little reduction in the blood pressure. When the blood flow determinations were repeated later ( 56 to 135 days) in these same four patients, it was found that comparatively little change had occurred in any of them (Table I-A). The remaining case (Case 1), when examined, had a renal blood flow of $965 \mathrm{cc}$. per minute, representing an increase over the pre-nephrectomy value of 720 cc. per minute. The observation that the renal blood flow in one remaining kidney equalled or exceeded the flow of both kidneys before nephrectomy in four out of five of these cases suggests that the remaining kidney, after nephrectomy, increased its flow. The pre-nephrectomy determinations of the flow of single normal kidneys in Cases 1, 4 and 5 (Table I-B), and a comparison of these determinations with those taken after the nephrectomy, indicate without much question that the flow had actually increased in the remaining kidney. For in Cases 1,4 and 5, the renal blood flow was 638,659 and 334 cc. per minute, respectively, before, and 965 , 1025 and 422 cc. per minute, respectively, after the nephrectomy. Finally, it should be emphasized that, despite the fact that the last renal blood flow determinations upon Cases 1, 3 and 4 indicate that there was no renal ischemia (even if it is assumed that the remaining kidney had hypertrophied to almost twice normal size), these patients were hypertensive at the time of the last clearance examination.

In each of the four cases studied immediately after the nephrectomy (13 to 19 days), there was a reduction in the inulin clearance (Table I-A). Before operation the clearances varied from 78.0 to $132.0 \mathrm{cc}$. per minute ; after operation, from 63.5 to $90.0 \mathrm{cc}$. per minute. When these four patients were re-examined later (56 to 135 days), it was found that the clearance had increased in Cases 2,4 and 5 , and decreased in Case 3 . In the remaining patient (Case 1 ), the inulin clearance was $133.0 \mathrm{cc}$. per minute, a value much higher than that observed prior to the removal of the affected kidney. Examination of the data in Table I-B indicates that the remaining kidney actually had increased its ability to excrete inulin. 
The maintenance of a relatively unchanged or increased renal blood flow and a diminution in the inulin clearance in Cases 2, 3 and 4 immediately after nephrectomy (13 to 19 days) effected a reduction in the filtration fraction. In Cases 2 and 3 , the reduction was quite marked (Table I-A), but in Case 4 , because of the relatively small change in the inulin clearance, there was only a decrease of 4 per cent in the filtration fraction. In Case 5, where not only the inulin clearance but also the renal blood flow decreased after operation, there was also a decrease of 4 per cent in the filtration fraction. On re-examination later (56 to 135 days), however, the filtration fraction was observed to have increased in Cases 2, 3, 4 and 5. In the remaining case (Case 1), the filtration fraction was 20.9 per cent, a value slightly lower than the one found before nephrectomy.

\section{DISCUSSION}

In a previous study of hypertensive patients without unilateral kidney disease (10), it was found that there was usually, but not always, a reduction in renal blood flow, a relatively normal glomerular filtration rate and a high filtration fraction. In the present series, the renal blood flow also was reduced in four of the five patients, but the inulin clearance was reduced in two, with a concomitantly lower filtration fraction. Because of this variability it is apparent that the diodrast and inulin clearance tests will not afford a positive clue as to the presence or absence of unilateral kidney disease, unless the kidneys are evaluated separately. If the latter is done, there will probably be a diminution in the diodrast and inulin clearances in the diseased kidney as compared to the clearances obtained from the opposite kidney.

The removal of the diseased kidney in the five patients studied resulted in an increase in the blood flow and in the glomerular filtration rate of the remaining kidney in each of the five cases, despite the fact that several types of kidney lesions were present in this series of patients.

Although the nephrectomy was followed by unquestioned reduction of the blood pressure in three of the five cases, there was slight or no improvement in the remaining two. Also, varying degrees of hypertension remained in all five patients.
Despite the fact that there was no ischemia of the remaining kidney following nephrectomy in three of the five patients, hypertension was found to be present in all of them. The presence of hypertension without renal ischemia in these patients, and the occasional demonstration of a similar state of affairs in the hypertensive patient without unilateral kidney disease (10), are suggestive evidence that renal ischemia may be a concomitant, but not necessarily a causative factor in the pathogenesis of human hypertension. The production of experimental renal hypertension in dogs (11) without the initial or later occurrence of renal ischemia further strengthens this view.

\section{CONCLUSIONS}

1. The total diodrast clearance was found to be reduced in four out of five patients having unilateral kidney disease with hypertension. It was more reduced in the affected kidney than in the normal one. The total inulin clearance was diminished in two, and normal in the remaining three patients.

2. The removal of the diseased kidney was followed by an increase in the renal blood flow and in the glomerular filtration rate of the remaining kidney in all five patients.

3. There was a significant blood pressure reduction in three of the five patients, but in none was there a complete return of the blood pressure to normal when last examined, despite the fact that in three of these patients there was no ischemia of the remaining kidney.

The authors wish to express their thanks to Doctors C. Johnson and W. J. Kerr of the University of California Medical School, and to Doctors L. Emge, T. Addis, W. Beckh and W. A. Sumner of the Stanford Medical School for their cooperation in making several of these patients available for study. We are indebted to Dr. A. Coxe of Stanford Medical School and Dr. G. Rusk of Mount Zion Hospital for their aid in the pathological study herein reported.

\section{BIBLIOGRAPHY}

1. Butler, A. M., Chronic pyelonephritis and arterial hypertension. J. Clin. Invest., 1937, 16, 889.

2. Backer, N. W., and Walters, W., Hypertension associated with unilateral chronic atrophic pyelonephritis. Treatment by nephrectomy. Proc. Staff Meet., Mayo Clin., 1938, 13, 118. 
3. Braasch, W. F., Walters, W., and Hammer, H. J., Hypertension and the surgical kidney. J. A. M. A., 1940, 115, 1837.

4. Leadbetter, W. F., and Burkland, C. E., Hypertension in unilateral renal disease. J. Urol., 1938, 39, 611.

5. Crabtree, E. G., and Chaset, N., Vascular nephritis and hypertension. J. A. M. A., 1940, 115, 1842.

6. Schroeder, H. A., and Fish, G. W., Studies on "essential" hypertension; the effect of nephrectomy upon hypertension associated with organic renal disease. Am. J. M. Sc., 1940, 199, 601.

7. Wilson, C., and Byrom, F. B., Renal changes in malignant hypertension; experimental evidence. Lancet, 1939, 1, 136.
8. Friedman, B., Jarman, J., and Klemperer, P., Sustained hypertension following experimental unilateral renal injuries. Effects of nephrectomy. Am. J. M. Sc., 1941, 202, 20.

9. Friedman, M., Selzer, A., and Rosenblum, H., The renal blood flow in coarctation of the aorta. J. Clin. Invest., 1941, 20, 107.

10. Friedman, M., Selzer, A., and Rosenblum, H., The renal blood flow in hypertension. J. A. M. A., 1941, 117, 92.

11. Friedman, M., Sugarman, H., and Selzer, A., The relationship of renal blood pressure and renal blood flow to the production of experimental hypertension. Am. J. Physiol., 1941, 134, 493. 